\title{
$\mathrm{PH} 101_{\text {debate }}$
}

a debate Hacia una nueva institucionalidad cultural. Modelos emergentes de gestión...

| coordina Jesús Carrillo Castillo

\section{Las relaciones entre las instituciones culturales y su territorio de inserción: del aislamiento a la hibridación}

\author{
Sergio Reyes-Corredera | Grupo de Investigación HUM-776 Análisis Geográfico, Universidad de Málaga
}

URL de la contribución <www.iaph.es/revistaph/index.php/revistaph/article/view/4723>

En la permanente relación institución cultural/territorio de implantación se aprecia un espectro de interrelación que está comprendido entre los extremos de la hibridación y el aislamiento. El primero de estos extremos hace referencia a la capacidad de generar tejido urbano cultural más allá de los muros de los edificios institucionales, mientras que el segundo se ciñe a su origen más etimológico, el de la isla, es decir, no enraizarse con el espacio urbano o el territorio en el que se inserta la institución. Esta cuestión lleva a plantearse cómo fomentar la hibridación, entendiendo esta como un aspecto positivo que refuerza la diversificación social y económica del lugar. Desde esta perspectiva, se percibe como muy
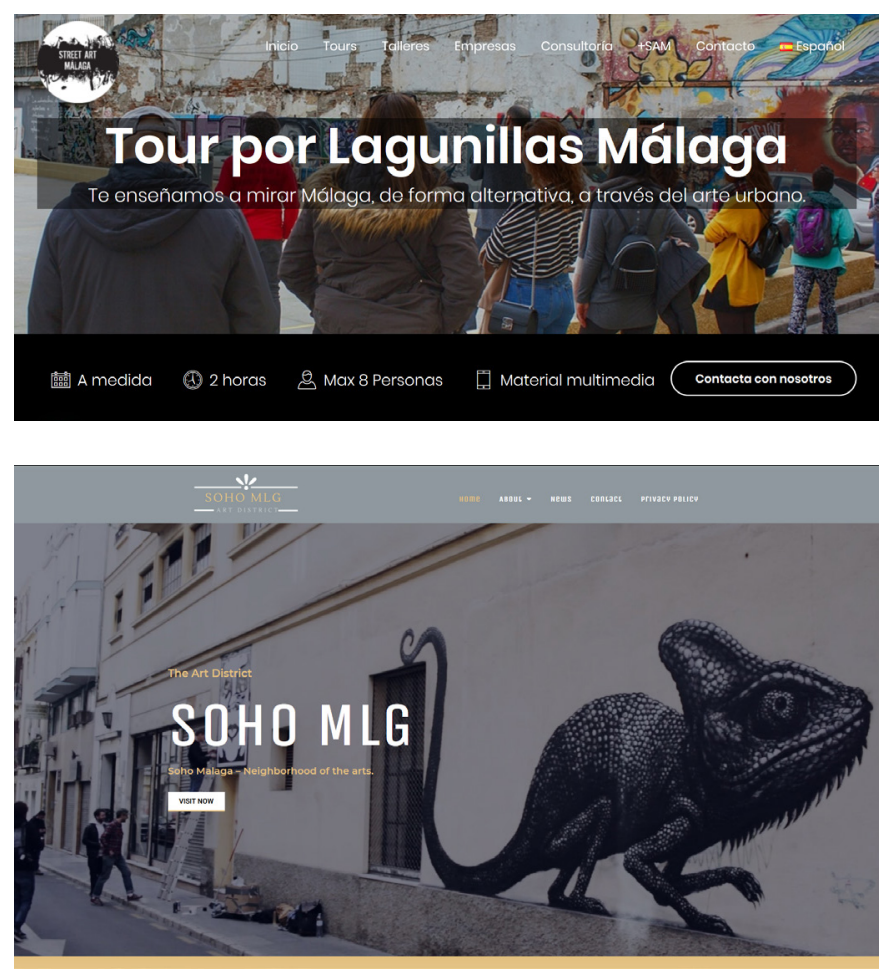

necesario implementar y fomentar los encuentros con la sociedad y los agentes económicos zonales. En el caso de la sociedad, pueden partir de encuentros con los colegios del área de inserción o el sondeo de los intereses culturales de la población empadronada más próxima a la institución, con la finalidad de llegar a puntos de encuentro en el que el beneficio sea mutuo. Otra alternativa a estas propuestas sería la de actuar en los barrios o pueblos de un modo proactivo; es decir, sacar la institución a la calle y trazar una senda que vehicule la relación barrio/pueblo con la institución haciéndose parte de esta. Este tipo de acciones harían valer ya no solo la utilidad de la institución para la ciudadanía próxima sino la importancia de disponer de instituciones culturales en el desarrollo social y económico de dicha ciudadanía animando a la generación de modelos de ciudad multifuncionales que vayan más allá del hábitat, de lo comercial o de lo industrial, algo que se ha puesto de relieve por parte de las políticas urbanas y rurales comunitarias (ETE, 1999).

En los últimos años, tras observar múltiples casos en Andalucía, se pueden percibir distintos niveles de hibridaciones urbanas o territoriales en relación con las instituciones culturales presentes:

> Hibridación plena: es el caso de los centros autogestionados culturales en los que la ciudadanía toma un espacio y genera cultura con los medios de los que dispone. Los más claros ejemplos andaluces los tenemos en colectivos como La Invisible (Málaga) o los movimientos culturales del Barrio de Lagunillas (Málaga) y el de la Casa del Pumarejo (Sevilla).

> Hibridación con dominante institucional: se genera una marca de la institución cultural que trasciende al espa- 
cio en el que se inserta, como es el caso de Entorno Thyssen en Málaga.

$>$ Hibridación con dominante gubernamental: se fomenta desde una corporación local la cultura y trasciende a un espacio determinado por la misma, es el caso de la localidad serrana de Genalguacil con el modelo de pueblo-museo.

> Hibridación mixta: se generan o renuevan instituciones culturales; es el caso del SOHO del ensanche Heredia del centro de Málaga, capaz de atraer inversiones culturales a través de una propuesta local que es fomentada por una corporación municipal. Esta última puede llegar a ser cuestionable en función de la evolución de las relaciones ciudadanía-institución puesto que acaban por generarse descompensaciones que derivan en fuertes procesos de gentrificación y de turistificación que desdibujan el fin que perseguía la sociedad impulsora, a pesar de poder generar una economía de marca local en un área de la ciudad.

La actual situación de pandemia mundial va a invitar a que las instituciones culturales vayan a tener que adaptarse físicamente y también al mercado y a la sociedad más próxima, dadas las condiciones de confinamiento administrativo a las que se están viendo expuestas, con los controles fronterizos y las restricciones de movilidad temporales en función de los rebrotes y las relaciones de cooperación entre países. Todo ello va a llevar a que exista una adaptación a los públicos de mayor proximidad (tenemos un claro ejemplo en las propuestas de autocines que están surgiendo desde las instituciones como el FAN CINE de Málaga; RVV, 2020) lo que debe traducirse en una reconducción o una reinvención de su oferta atendiendo a los medios de transporte más menos expuestos, como la bicicleta (MÁLAGA, 2020); controlando los aforos; ofreciendo alternativas en espacios exteriores como exposiciones al aire libre; e insertándose en los tejidos populares, evitando modelos aislados museísticos, como ha ocurrido con el complejo de Tabacalera, en el sector litoral occidental de la ciudad de Málaga, que no ha tenido ninguna trascendencia en los barrios populares de la ciudad y solo se ha conectado, a través de líneas de transporte público, con los visitantes que centran su visita en el casco histórico de la ciudad. Por el contrario, este espacio podría haber incidido en los centros educativos de la zona e, incluso, en los espacios libres existentes (paseo marítimo de poniente o Parque de Huelin), como podría ocurrir con la propuesta de un Bosque Urbano en los terrenos de la antigua REPSOL o como de hecho ha sucedido con otros espacios culturales existentes, como el caso de La Térmica en la sede de la Diputación de Málaga.

Para concluir, es necesario realizar una apuesta por insertar de modo real las instituciones en los tejidos urbanos y rurales que esté en consonancia con la ciudadanía que habita estos espacios. De esta forma, se fomentaría una hibridación que genere una diversificación funcional de estas áreas, fortaleciendo la respuesta socioeconómica ante futuros rebrotes derivados de la actual situación de pandemia pero, también, de fluctuaciones de la demanda en función de otras causas sociales o económicas.

\section{BIBLIOGRAFÍA}

- ETE (1999) Estrategia Territorial Europea: Hacia un desarrollo equilibrado y sostenible del terriotorio de la UE [en línea]. Potsdam: Comisión Europea, 1999 <https://ec.europa. eu/regional_policy/sources/docoffic/official/reports/pdf/sum_ es.pdf> [Consulta: 14/07/2020]

- MÁlAGA y el fomento de la bici durante el COVID19 (2020). En Ruedas redondas [en línea], May 26, $2020<$ https:// ruedasredondas.org/malaga-y-el-fomento-de-la-bici-duranteel-covid19/> [Consulta: 15/07/2020]

- RVV (2020) Fancine llega puntual a sus tres décadas de vida. Málaga hoy [en línea] 10 julio, 2020 <https://www.malagahoy. es/ocio/Fancine-tres-decadas-vida_0_1481252359.html> [Consulta: 15/07/2020] 